\title{
The Characteristics of Times of Shiji Dramas in Legendary Opera of Ming Dynasty
}

\author{
Wei Dai \\ College of Chinese Language and Literature, Northwest Normal University, Lanzhou 730070, China
}

Keywords: Shiji Dramas, Characteristics of Times, Advocate Legendary, Confrotation of Emotion and Neo-Confucianism

\begin{abstract}
The Chuanqi Opera in Ming Dynasty is an important link in the chain of ancient Chinese operas. Shiji Opera is one of the themes of Chuanqi Opera in Ming Dynasty. It not only inherited the gene of Shiji, also disseminated the spirit of the times and has distinct characteristics of the times. It is mainly manifested in two aspects: "advocate legendary" and "confrotation of emotion and Neo-Confucianism". It indicates the unique aesthetic style of the Ming Dynasty and characteristics of these times. At the same time, it is also the reflection of ideological and cultural changes in drama art.
\end{abstract}

\section{Introduction}

It is a common phenomenon in the society that people in Ming Dynasty are still "advocate legendary".Mr. Yingde Guo thinks, "inspired by modern cultural thought, under the impact of modern aesthetic interest, under the influence of modern turbulent society, from the booming period, the Chaunqi writers of literati have produced a strong rebellious mentality, seeking to break away from the norms of the network, boldly seeking novelty in the creation of Chuanqi Opera." ${ }^{[1]}$

\section{Advocate Legendary}

In the theoretical concept of Chuanqi writers in the Ming Dynasty, "legendary" is an artistic effect from inside to outside, which is expressed by Chuanqi Opera, in other words, "legendary" is the essential feature of Chuanqi Opera. It includes two points: one is odd and strange, that is, strange characters and strange plot. The two is a peculiar style of writing, this is from the way of expression.

\subsection{Strange characters and things are strange}

In the Shiji opera, most of the characters come from Shiji, and Sima Qian himself has strong " advocate legendary " tendencies, so Shiji is also called "legendary book". However, as a historical work, it is impossible for Shiji to depict every strange person and every things comprehensively and meticulously, its omissions is an excellent material for historian playwrights. In this case, we take "Qiefu Ji" as an example, to analyze how the historian writers created strange people and constructed strange things.

$\mathrm{Ru} \mathrm{Ji}$ in Shiji, is the appearance of a legendary woman. But Ru Ji's image in the biography is very thin, neither a comprehensive introduction to her life story, nor a detailed description of her personality characteristics, even the consequences of her theft of a soldier's identity were not known. In Qiefu Ji, in order to make the strange and thin image of Ruji fuller, Zhang Fengyi, a writer, fully utilized the artistic techniques of addition, fiction and affiliation to reconstruct and modify the image of Ru ji. In Qiefu Ji, Ru Ji was born poor and her father was murdered, she wanted revenge, but it was difficult to do so,so she asked the XinLing Jun to revenge her father, and said that as long as revenge is successful, sacrifice is no harm, then XinLing Jun presented the enemy's head, such as Ji's resentment, which was just like the heavy filial piety of $\mathrm{Ru}$ Ji. However, $\mathrm{Ru} \mathrm{Ji}$ in the play "more" understanding report, XinLing Jun begged her to steal soldier's identity to save Zhao, she knew that this would certainly lead to death. After the incident was exposed, the king of Wei 
tortured maid severely, Ru Ji with sympathy, voluntarily confessed his actions to the king of Wei, willing to accept crimes, which is as good as Ru Ji. Yan En, the inner envoy, was sent to XinLing Jun by Ruji, the king of Wei wanted to kill Yan En, Ruji falsely claimed that Yan En was given a sachet to XinLing Jun's wife., Yan En did not know that the sachet was inside and saved Yan En's life,this was Ruji's wisdom. Under the portrayal of the writer Zhang Fengyi, the image of RuJi was immediately flesh and blood on paper.

Except to the strange man, the book is more constructed strange affair clearly. There are two stories in the book of Qiefu Ji: steal soldier's identity to save Zhao, resistance to the Qin and to save Wei. But Zhang Fengyi put more emphasis on the former, why did he do that? The reason lies not only in the important position of stealing soldier's identity to save Zhao in history, but also in the legendary nature of the event itself. At that time, Qin troops encircling Handan, the PingYuan Jun and his wife asked for help from King of Wei and XinLing Jun, King of Wei is threatened by the King of Qin, dare not help. On the occasion of the crisis, Hou Ying offered a stratagem of theft for XinLing Jun. The reason why this strategy is legendary and fascinating is the word "stealing", extraordinary things have been acquired by extraordinary meansa nd thus gained a special right, the acquisition of such right is a risk of decapitation. The design of stolen is closely related. But Shiji only depicts the rough clues of the theft, which is not exhaustive, however, Qiefu Ji has played the artistic characteristics of describing the event in depth and meticulously, within the framework of the original story, it is a vivid and realistic wonder to convey blood and build muscles for the theft by means of fiction, kneading and fabrication. When the playwright tells the story of stolen, he can dig and exploit it it deeply, show the whole story and details one by one, and form a close logical relationship between the size and details, which greatly improves the rationality and authenticity of the story,and the size of the details of the composition of a close logical relationship, its rationality, authenticity has been greatly improved, in line with the reality of life and the audience's aesthetic, such a legendray story constituted.

\subsection{Strange article}

That is, the writing method is odd.1. Use an ambush pen. Ru Ji thought of his kindness and prayed for he. But at the end of this section, she said to Yan Yan:" if necessary, let me know." ${ }^{[2]}$ This sentence is definitely not the casual words of author Zhang Fengyi, but is intended for it. It can provide foreshadowing for the theft, so that it can be justified, but it does not appear abrupt.2. Inverted sequence of plots. In the biography of the XinLing Jun, the plot of the game between Xin Ling Jun and King of Wei was arranged before Xin Ling Jun invite Hou Ying. But in Qiefu Ji, the order of the two is reversed. This tiny change in layout bring remarkable results. Xin Ling Jun is playing chess with king of Wei, Zhao troops suddenly went to the frontier, and the king of Wei was startled. He wanted to call the minister to discuss the strategy of resisting the enemy. However, Xin Ling Jun said very calmly:" the king of Zhao hunting in southern suburbs, so you panic in the north." After this, the King of Wei had jealousy for XinLing Jun. When the King of Wei had a distrust of XinLing Jun, Qin would kill 400,000 Zhao troops in the battle of Changping, and Zhao was in danger. However, the King of Wei was forced by the Qin Kingdom to engage in immoral rescue and did not launch substantive rescue to Zhao. After the reversal of the plot, the causal relationship is clear, close and coherent, the crisis is urgent, and the situation of the swords is lively on paper, not only proves the dimness and cowardice of the King of Wei, but also reflects the XinLing Ling's desperate dedication to safeguarding national interests.

\section{Confrotation of Emotion and Neo-Confucianism}

In the early Ming Dynasty, Cheng Zhu Neo-Confucianism occupied an absolute dominant position in the ideological circles, influenced by it, most traditional operas advocated feudal ethics and moral education. Such as Pipa Ji, Wulun Quanbei Ji, Xiangnang Ji.

Since the middle and late Ming Dynasty, the ruling class has been decaying day by day, the commodity economy has been developing rapidly, the capitalist relations of production have sprouted, new ideas have sprung up, a trend of opposing the fetters of Neo-Confucianism, 
advocating natural humanity and affirming the human desire for material things has been prevalent in the ideological and cultural circles. This trend of thought swept across the country and penetrated into all aspects of social life. The main reason for its formation was the spread of Wang Yangming's theory of mind. Wang Yangming attempt to transplant feudal order, morality and ethics into people's hearts has become their internal needs, not their external constraints. But "the principle of "mind is reason" is becoming increasingly perceptual, increasingly, from external heavenly principles, norms and order to inner nature, emotion and even desire." ${ }^{[3]}$ Echoing this philosophy of human desire, the literary trend of "emotion" has been raised in the literary world, the "emotiont" is the sentiment of nature and human nature, and is a bold break from the fetters of the feudal ethics. This is especially prominent in the QinXin Ji.

The QinXin Ji takes the story of the elopement in Sima Xiangru an Zhuo Wenjun, blends the distinct characteristics of the times, and vigorously sings the love between the two. The central conflict in QinXin Ji is the confrontation between love as human nature and feudal moral concepts that bind human body and mind. In terms of Sima Xiangru an Zhuo Wenjun, Xiangru handsome and talented, Wen Jun is rich, smart and demure, the two people disregard the family status and then elopement together. Even after being faced with the poverty, Wen Jun never left behind, but they depended on each other. As an independent love story, its romantic practice of elopement has broken through the rules and regulations of feudal ethics, with the characteristics of personality liberation, which is in line with the cultural trend of thought in the late Ming Dynasty. In terms of QinXin Ji, the author praises the sincere love of Xiangru and Wenjun, affirms their free love behavior, and expresses their inner world of longing for love and bold pursuit of love. Xiangru and Wenjun, they interpreted each other's musical sounds, exchanged their ideas, ignored the feudal ethics and morals, and loved each other for life, which embodied the yearning for true love. In the face of villains teasing and feudal parents'siege, Wenjun did not yield, she rebelled against the feudal orthodox forces in the way of becoming a nun, reflecting the incompatibility between emotion and reason. It is worth noting that Wen Jun's elopement at night is achieved by jumping through walls, it shows the courage of two people to break through the yoke of ritual and bondage. For Xiangru, facing the seduction and flirtation of women, he did not move, and firmly guarded Wenjun's love.

What reflects love and feudal ethics and morals, and wins by love, is also reflected in Zhang Fengyi's GuanYuan Ji. When JunWANG Hou knowing Wang Li's true identity, she was in private with FA Zhang, and even had sex with him. This is further than QinXin Ji, it shows the awakening of human nature and the rationality of human desires.

\section{Conclusions}

Shiji opera not only inherited the "advocate legendray", but also disseminated the spirit of the times, with distinctive characteristics of the times. It is mainly manifested in two aspects: "advocate legendary" and "confrotation of emotion and Neo-Confucianism". They reflect the aesthetic taste of the Ming Dynasty, it is the embodiment of the change of thought in drama.

\section{References}

[1] Guo Yingde. A Study of Literati Chuanqi Opera of Ming and Qing Dynasty[M] Beijing Normal University Press.2001(230-231)

[2] Zhang Fengyi. Zhang Fengyi’s Opera Collection[M] Zhong Hua Book Company.1994(255)

[3] Guo Yingde. A Study of Literati Chuanqi Opera of Ming and Qing Dynasty[M] Beijing Normal University Press.2001(97) 